\title{
Enhancing arsenic mitigation in Bangladesh: Findings from institutional, psychological, and technical investigations
}

\author{
Richard Johnston a,*, Stephan J. Hug ${ }^{b}$, Jennifer Inauen ${ }^{c}$, Nasreen I. Khan ${ }^{d}$, Hans-Joachim Mosler ${ }^{e}$, Hong Yang ${ }^{f}$ \\ a Eawag-Swiss Federal Institute of Aquatic Science and Technology, Sandec, Department of Water and Sanitation in Developing Countries, Switzerland \\ ${ }^{\mathrm{b}}$ Eawag-Swiss Federal Institute of Aquatic Science and Technology, Department of Water Resources and Drinking Water, Switzerland \\ c University of Zurich, Department of Psychology, Switzerland \\ d Fenner School of Environment and Society, The Australian National University, Canberra, ACT 0200, Australia \\ e Eawag-Swiss Federal Institute of Aquatic Science and Technology, Department of Environmental Social Sciences, Switzerland \\ ${ }^{\mathrm{f}}$ Eawag-Swiss Federal Institute of Aquatic Science and Technology, Department of System Analysis, Integrated Assessment and Modelling, Switzerland
}

\section{H I G H L I G H T S}

- Institutional, psychological, and technical aspects of arsenic mitigation were studied.

- Both institutional stakeholders and populations at risk supported deep tubewells.

- Self-efficacy and social norms drive behavior and are supportive of deep tubewells.

- Deep groundwater can provide drinking-water free from arsenic and other chemicals.

- Higher priority should be given to installing deep tubewells in high-risk areas.

\section{A R T I C L E I N F O}

\section{Article history:}

Received 31 May 2013

Received in revised form 26 November 2013

Accepted 27 November 2013

Available online 28 December 2013

\section{Keywords:}

Arsenic

Groundwater

Tubewell

Bangladesh

Behavior change

Institutional analysis

\begin{abstract}
A B S T R A C T
As part of a trans-disciplinary research project, a series of surveys and interventions were conducted in different arsenic-affected regions of rural Bangladesh. Surveys of institutional stakeholders identified deep tubewells and piped water systems as the most preferred options, and the same preferences were found in household surveys of populations at risk. Psychological surveys revealed that these two technologies were well-supported by potential users, with self-efficacy and social norms being the principal factors driving behavior change. The principal drawbacks of deep tubewells are that installation costs are too high for most families to own private wells, and that for various socio-cultural-religious reasons, people are not willing to walk long distances to access communal tubewells. In addition, water sector planners have reservations about greater exploitation of the deep aquifer, out of concern for current or future geogenic contamination. Groundwater models and field studies have shown that in the great majority of the affected areas, the risk of arsenic contamination of deep groundwater is small; salinity, iron, and manganese are more likely to pose problems. These constituents can in some cases be avoided by exploiting an intermediate depth aquifer of good chemical quality, which is hydraulically and geochemically separate from the arsenic-contaminated shallow aquifer. Deep tubewells represent a technically sound option throughout much of the arsenic-affected regions, and future mitigation programs should build on and accelerate construction of deep tubewells. Utilization of deep tubewells, however, could be improved by increasing the tubewell density (which requires stronger financial support) to reduce travel times, by considering water quality in a holistic way, and by accompanying tubewell installation with motivational interventions based on psychological factors. By combining findings from technical and social sciences, the efficiency and success of arsenic mitigation in general - and installation of deep tubewells in particular - can be significantly enhanced.
\end{abstract}

(C) 2013 Elsevier B.V. All rights reserved.
* Corresponding author at: Eawag-Swiss Federal Institute of Aquatic Science and Technology, Sandec, Department of Water and Sanitation in Developing Countries, Ueberlandstrasse 133, CH-8600 Dübendorf, Switzerland.

E-mail addresses: johnstonr@who.int (R. Johnston), Stephan.hug@eawag.ch (S.J. Hug), jennifer.inauen@psychologie.uzh.ch (J. Inauen), nasreen.khan@anu.edu.au (N.I. Khan), hans-joachim.mosler@eawag.ch (H.-J. Mosler), hong.yang@eawag.ch (H. Yang).

\section{Introduction}

The importance of geogenic contamination of drinking-water only became evident upon discovery of widespread arsenic contamination in Bangladesh in the 1990s. The National Hydrochemical Survey of 2000 (BGS/DPHE, 2001) found that naturally occurring arsenic was widespread in the shallow aquifer (less than $150 \mathrm{~m}$ in depth) but largely absent from 
deeper groundwater. Water samples (from shallow and deep tubewells) exceeded the WHO provisional Guideline Value of $10 \mu \mathrm{g} / \mathrm{L}$ and the Bangladesh Drinking Water Standard of $50 \mu \mathrm{g} / \mathrm{L}$ in $42 \%$ and $25 \%$ of samples, respectively. $8.9 \%$ of samples contained more than $200 \mu \mathrm{g} / \mathrm{L}$, up to a maximum of $1660 \mu \mathrm{g} / \mathrm{L}$. The authors estimated that out of a total population of 125 million people, 35 million people were exposed to water above $50 \mu \mathrm{g} / \mathrm{L}$, and 57 million people were exposed above $10 \mu \mathrm{g} / \mathrm{L}$

These findings spurred a series of high-profile mitigation efforts. However, after an initial period of intense focus on arsenic, attention drifted away, both at the local and national scales. The main arsenicspecific project during this period was the Bangladesh Arsenic Mitigation and Water Supply (BAMWSP) project, supported by the World Bank. Running from approximately 1998 through 2007, BAMWSP spent approximately $\$ 22$ million on testing, patient identification, and installation of alternative drinking water supply options. In 2004, the government issued a National Policy for Arsenic Mitigation (GOB, 2004a) and Implementation Plan for Arsenic Mitigation (GOB, 2004b). The National Policy stated that mitigation efforts should give preference to surface water over groundwater as a water supply source, and that piped water systems should be promoted wherever feasible. The Implementation Plan was more explicit with respect to groundwater; it stated that in coastal areas where the deep aquifer had been well characterized, deep tubewells could be used for arsenic mitigation, but in other areas (including most of the highly affected zones), surface water or very shallow groundwater should be tried first. Thus early mitigation efforts focused on technologies such as pond sand filters and hand-dug wells. While these water sources are largely free from arsenic, they are more vulnerable to fecal contamination. Lokuge et al. (2004) argued that switching from arsenic-contaminated groundwater to fecally-contaminated unimproved sources could actually increase the burden of disease; (Howard et al., 2006) surveyed different arsenic mitigation options and calculated the burden of disease expected from arsenic and microbial contamination, expressed in DisabilityAdjusted Life Years (DALYs). In comparison to shallow tubewells, deep tubewells were predicted to cause a much lower burden of disease; rainwater collection had a lower burden from arsenic but higher burden from microbial contamination leading to an overall similar burden; and both dug wells and pond sand filters lead to approximately an order of magnitude more disease, wholly attributable to poor microbial quality. These findings lent support to the already widespread practice of giving preference to deep tubewells over other sources in mitigation programs. Piped water systems are a new phenomenon in rural Bangladesh, and there is so far little documented experience on either the financial sustainability of such systems, or the quality of water they are able to deliver. Experiences from other countries suggests that intermittently operated piped water schemes are vulnerable to fecal contamination, and do not necessarily deliver water which is safer than point sources (Klasen et al., 2012).

By 2009 180,000 alternative water sources had been installed in arsenic-affected areas. Using estimates of the population served by each technology, over 11 million people were estimated to have arsenic-free water in the affected areas (DPHE/JICA, 2009).

Capital costs of all of these alternatives are several times higher than for shallow tubewells, so while individual households can relatively easily afford private shallow tubewells, only wealthy families enjoy their own deep tubewells. Government programs (by far the largest contributor to deep tubewell installation) ask communities to contribute about $10 \%$ of the capital costs for installation of communal deep tubewells. However, these water points have not been preferentially sited in the worst-affected areas: $61 \%$ of the safe water supplies were installed in the $16 \%$ of unions where fewer than $20 \%$ of tubewells were contaminated (DPHE/JICA, 2009). If these water sources had been installed in more highly affected areas, exposure could have been reduced more efficiently.
In 2009, a second national survey (UNICEF/BBS, 2011) was conducted, which found much less arsenic (Table 1). These figures are encouraging, and suggest that exposure may have been reduced by roughly a quarter at the $10 \mu \mathrm{g} / \mathrm{L}$ level, and by greater factors at higher levels (Table 2). During the same period, the population increased by nearly a third. Taking the population-adjusted figures, it seems that the number of people exposed to the highest levels $(>200 \mu \mathrm{g} / \mathrm{L}$ ) has been reduced by more than one half, and the population drinking water not meeting national standards reduced by approximately one third. Considering the stricter $10 \mu \mathrm{g} / \mathrm{L}$ level, however, progress is only just keeping up with population growth. However, these gains may be overstated: the 1999 survey measured arsenic at the water source, and the 2009 measurements were made on water samples collected in households. While the lower contamination levels could reflect people systematically switching to less contaminated sources, it is also possible that arsenic levels can be slightly reduced during household storage, due to oxidation and precipitation of iron which can scavenge arsenic from solution.

While arsenic exposure has clearly been reduced, mitigation has proceeded much more slowly than originally hoped and planned, and the public health burden remains unacceptably high. Health impact models suggest that at least 24,000 deaths per year are caused by arsenic (Flanagan et al., 2012), which is larger than the number of child deaths caused by diarrheal disease (National Institute of Population Research and Training (NIPORT) et al., 2013). Reducing this disease burden should be a high priority for the government and development partners.

Mitigation of arsenic in drinking water is a complex task, involving a broad spectrum of stakeholders, from policy makers, regulators, facilitators, implementers, to social groups and end users of water. The selection of suitable mitigation measures and the ways they are implemented all have significant impact on the results of the mitigation. In practice, it is important to involve stakeholders from the whole range of the spectrum and at all stages in the process to ensure that the measures implemented are the most preferred. This leads to a need for integrated analysis of individual measures from the aspects of institution compatibility, economic viability, household acceptability, and technical feasibility. Such information is essential for a successful implementation of mitigation measures to effectively reduce arsenic contamination in drinking water. This manuscript presents findings from three related research projects which explored institutional, psychological, and technical factors which could enhance (or retard) the rate of arsenic mitigation in Bangladesh.

\section{Arsenic mitigation: Institutional stakeholders perspective}

There is no doubt that bringing tens of millions of people exposed to arsenic under safe water coverage is an immensely complex and expensive task. Therefore, understanding of this issue by institutional

Table 1

Alternative water supplies in arsenic-affected areas (excluding shallow tubewells) (DPHE/ JICA, 2009).

\begin{tabular}{lrrlrr}
\hline Alternative water source & $\begin{array}{l}\text { Number } \\
\text { active }\end{array}$ & & $\begin{array}{l}\text { Population } \\
\text { served per } \\
\text { source }\end{array}$ & $\begin{array}{l}\text { Estimated } \\
\text { population } \\
\text { served } \\
\text { ('000) }\end{array}$ & \\
\hline Deep tubewells & 164,652 & $91.2 \%$ & 65 & 10,702 & $91.2 \%$ \\
Dug wells & 9163 & $5.1 \%$ & 40 & 367 & $3.1 \%$ \\
Pond sand filters & 3431 & $1.9 \%$ & 90 & 309 & $2.6 \%$ \\
Arsenic/iron removal plants & 182 & $0.1 \%$ & 65 & 12 & $0.1 \%$ \\
Rainwater harvesting & 3045 & $1.7 \%$ & 5 & 15 & $0.1 \%$ \\
$\quad$ systems & 134 & $0.1 \%$ & 2500 & 335 & $2.9 \%$ \\
$\quad \begin{array}{l}\text { Rural piped water schemes } \\
\text { Total }\end{array}$ & 180,607 & & & 11,740 & \\
\hline
\end{tabular}


Table 2

Exposure to arsenic through drinking water in Bangladesh (BGS/DPHE, 2001; UNICEF/BBS, 2011).

\begin{tabular}{lccc}
\hline & 1999 & 2009 & Change \\
\hline Proportion $>10 \mu \mathrm{g} / \mathrm{L}$ & $42.1 \%$ & $32.0 \%$ & $-24 \%$ \\
Proportion $>50 \mu \mathrm{g} / \mathrm{L}$ & $24.9 \%$ & $13.4 \%$ & $-46 \%$ \\
Proportion $>200 \mu \mathrm{g} / \mathrm{L}$ & $8.9 \%$ & $3.4 \%$ & $-62 \%$ \\
Population (millions) $>10 \mu \mathrm{g} / \mathrm{L}$ & 57 & 53 & $-8 \%$ \\
Population (millions) $>50 \mu \mathrm{L} / \mathrm{L}$ & 35 & 22 & $-37 \%$ \\
Population (millions) $>200 \mu \mathrm{g} / \mathrm{L}$ & 12 & 5.6 & $-55 \%$ \\
Total population (millions) & 125.5 & 164 & $+31 \%$ \\
\hline
\end{tabular}

stakeholders is crucial for sustainable arsenic mitigation in Bangladesh. Recently two structured face-to-face questionnaire surveys were conducted by Khan to collect institutional and household level stakeholders' opinions on various aspects of arsenic mitigation in Bangladesh. A stakeholder survey was conducted targeting officials from central and local government, NGOs, and donors involved in arsenic mitigation (Khan and Yang, 2013). In a second survey in 13 arsenic-affected rural villages from four upazilas (sub-districts), 650 household respondents were asked about their current and preferred water usage practices, as well as their willingness to pay for (and walk to) new alternative sources such as deep tubewells (Khan et al., Under review; Khan and Yang, 2013). Given the slow progress in arsenic mitigation, stakeholders were also asked about the major limiting factors to the mitigation activities in Bangladesh. In this section mainly institutional stakeholder survey results will be summarized with some reference to household survey results.

Stakeholders from all different types of organizations stated that their major roles were providing arsenic-free safe water and increasing awareness of arsenic contamination and exposure among the rural population. The majority (63\%) felt that one of their major achievements had been increasing awareness among the rural population regarding arsenic contamination, and that as a result of increased awareness activities demand for deep tubewells and other alternative arsenic-free safe water options had increased amongst the rural community. Other major achievements revealed by stakeholders included providing assistance on health care services related to arsenicosis problems (32\%) and introducing and ensuring safe water options (27\%).

Upazila parishad (sub-district councils) are locally elected government institutions which play a critical role in identifying and responding to arsenic contamination. However, stakeholders identified a lack of financial and technical capacity for effective response to arsenic contamination among upazila parishad staff; greater decision making power (37\%) and increased funds and allocation and retention of trained manpower (74\%) would strengthen capacity at the local government level and hence result in better performance (Khan and Yang, 2013).

Institutional stakeholders clearly identified deep tubewells and piped water systems as the most preferred options (95\% and 58\% respectively) for avoiding arsenic exposure through drinking water (Khan and Yang, 2013). A similar preference for deep tubewells has also been noted in the household level surveys (Khan et al., Under review), and by Shafiquzzaman et al. (2009). Stakeholders rated deep tubewells as being "highly suitable" (89\%) as a long-term safe water option followed by piped water systems (68\%). Rain water harvesting was also identified as a popular and suitable option in coastal areas of Bangladesh where groundwater salinity restricts water supply through either deep tubewells or piped water systems (Khan et al., Under review). However, household arsenic removal filters were identified as being a "not suitable" option by a majority of stakeholders (63\%), and the household level preference survey found that only $9 \%$ of households interviewed expressed their preferences for household filters as safe water option (Khan et al., Under review). None of the other water options (pond sand filters, dug wells, rainwater harvesting) were significantly favored by stakeholders; and overall $50 \%$ of the respondents considered other water options as being "not at all suitable" and only $10 \%$ considered any other water options as "highly suitable". The majority of the stakeholders (68\%) strongly preferred community based safe water option over individual household options (Khan and Yang, 2013).

Institutional stakeholder opinions on households' willingness to pay (WTP) and willingness to walk (WTW) to access safe water options were investigated (Khan and Yang, 2013). On average, stakeholders estimated that $50 \mathrm{BDT}^{1} /$ month (range 10-250 BDT/month) until full recovery of installation cost was made would be reasonable. These estimates matched well with household responses: Overall three quarters of the household respondents were willing to pay 25 (32\%) or 50 (42\%) BDT for monthly operation and maintenance costs. Household survey results indicated that study households were generally willing to pay up to $5 \%$ of their disposable average annual household income for a one-time investment (capital cost) towards construction of a deep tubewell (DTW) to receive arsenic-free drinking water (Khan et al., under review). This low value reflects the fact that in the rural villages in Bangladesh the concept of "paying for water" has not been completely developed because households can still obtain water without payment. Stakeholders stressed that regular awareness programs would help to develop the concept of "paying for water" in the rural community.

Spatio-temporal aspects (travel distance and travel time) are noneconomic costs of risk behavior. Willingness to Walk (WTW) also plays a vital role in determining the long-term sustainability and acceptance of the safe water option. The great majority of the institutional stakeholders (90\%) agreed that end-users should be willing to walk a certain distance for water, while only $10 \%$ believed that end-user should not walk at all for water. Most stakeholders believed that a range of 0-250 $\mathrm{m}$ and 10-30 min per trip was a reasonable distance and time for water collection, without unduly impairing the ability of women (traditionally responsible for water collection in Bangladesh) to efficiently manage their other household work. However, stakeholders also mentioned that religious and cultural issues are also principal factors restricting people's WTW for water. All of the survey respondents were Muslim and the study was not designed to quantitatively assess religious influences. As for cultural factors, in some areas of rural Bangladesh the women and girls are not encouraged by male family members to travel far outside the family home (bari). This can pose a barrier to the collection of water from public sources.

When asked the reasons for relatively slow progress in mitigation, the most common response was the lack of responsibility and accountability, identified by $32 \%$ of stakeholders. Insufficient funding, lack of coordination, shortage of skilled man power, were all considered as major limiting factors by about $25 \%$ of the stakeholders. Most institutional stakeholders believed that lack of accountability (32\%) and commitment $(11 \%)$ from both providers and end-users as well as a lack of coordination between organizations (26\%) were the key factors for unsustainable arsenic mitigation (Khan and Yang, 2013). Stakeholders were of the opinion that for sustainable effective arsenic mitigation by the upazila parishad, the effectiveness of existing arsenic coordination committees was crucial and that this could be enhanced by organizing regular meetings and involving experienced people regardless of their political affiliation. Stakeholders also agreed that arsenic mitigation should use a combination of different options suitable to different parts of Bangladesh and therefore, a single blanket mitigation option for the whole country would not be sustainable (Khan and Yang, 2013).

\section{Psychological aspects}

While institutional stakeholders may set policies or design programs for promoting different arsenic-free water sources, switching from an

\footnotetext{
${ }^{1}$ At the time of the survey in 2010, 100 Bangladeshi Taka (BDT) equaled USD 1.44.
} 
arsenic-contaminated shallow tubewell to a different water source is fundamentally a change in behavior, decided by individuals. We conducted a series of surveys in six arsenic-affected districts to investigate the acceptance and use of available arsenic-safe water options (Inauen et al., 2013a), the psychological factors leading to their use (Inauen et al., 2013b; Mosler et al., 2010), and to test behavior change interventions to increase their use (Inauen and Mosler, 2013; Inauen et al. 2013c).

\subsection{Which arsenic-safe water options do people use and why?}

While Table 1 shows that more than 180,000 safe water facilities had been installed as of 2009, the estimates of populations benefiting from these communal water points are based on administrative assumptions which are not well supported empirically. DPHE and JICA estimated that one dugwell should serve 40 people, one pond sand filter 90, and one deep tubewell 65 (DPHE/JICA, 2009). Yet in a survey in three arsenicaffected sub-districts, the median number of reported users for these three technologies was 50,180, and 350, respectively (Johnston and Sarker, 2007). It has rarely been reported how many of the affected households with access to any of these safe water options actually use them. Our study of eight arsenic-safe water options showed that overall, only $62 \%$ of households with access to a safe water option ( $\mathrm{N}=1268)$ actually use them (Inauen et al., 2013a). The study also revealed great discrepancies of user rates for the different water options. The most used options were piped water supply (used by $86 \%$ of households with access), community arsenic-removal filters (74\%), and wellsharing (71\%). Deep tubewells (54\%), dug wells (52\%), pond sand filters (48\%), and rainwater harvesting systems (37\%) were less frequently used. Clearly, if more people would use the options which are accessible to them, the public health burden would be reduced.

We have identified psychological factors from the RANAS (risk, attitudes, norms, abilities, self-regulation) model of behavior change (Mosler, 2012) that indicate deeper understanding of why some water options are more well-accepted than others (Inauen et al., 2013a). Piped water supply was most strongly supported by almost all psychological factors. In particular, households with access to piped water reported strong taste and temperature preferences, strong social norms (i.e. that many significant others are in favor of using arsenic-safe water sources, and that they are also using them), high confidence in their ability to obtain as much arsenic-safe water as needed (i.e. selfefficacy, Bandura, 1997), and high commitment (i.e. a personal urge, Inauen et al., 2013c) to consuming piped water. Interestingly, deep tubewells were also strongly accepted, despite only moderate user rates. This may be due to the fact that collecting water from deep tubewells has been reported as time-consuming, which may have led to lower commitment (Inauen et al., 2013c). However, distance is not the sole determining factor, as was shown by the low user rates of rainwater harvesting. The psychologically least supported options were dug wells, perceived as time consuming with taste and odor issues of the water, and well-sharing. Households with access to the latter, even though many of them used neighboring tubewells, reported belowaverage social norms for using them and low commitment. This may indicate that well-sharing fluctuates more than the use of other options, also because users are dependent on their neighbors' consent to use their tubewells. Based on these results, a series of interventions were suggested to enhance the use of each of the different arsenic-safe water options (Inauen et al., 2013a). While the recommendations from these descriptive results of people's acceptance is valuable for being very specific for each option, it may also be disadvantageous, because it was not shown, which psychological factors are most promising to target in interventions. Therefore, a model of the use of arsenic-safe water options was developed that can forecast the use of the options with the psychological factors (Inauen et al., 2013b).

In line with an earlier model of the use of deep tubewells (Mosler et al., 2010), self-efficacy, and the descriptive norm (i.e. how many people use arsenic-safe water options, Cialdini, 2003), emerged as the most important factors to explain the use of arsenic-safe tubewells (Inauen et al., 2013b). Further important factors were instrumental attitudes (i.e. perceiving water collection as time consuming and effortful), and the injunctive norm (i.e. what one thinks that others think should be done, Schultz et al., 2007). This was generalizable to all the seven arsenic-safe water options included in the study, indicating that behavior change interventions targeting self-efficacy and the descriptive norms will have the greatest impact on increasing use of an arsenicsafe water option (Inauen et al., 2013b). This finding was further corroborated by studies on the prediction and enhancement of well-sharing (Inauen and Mosler, 2013), and deep tubewell use (Inauen et al., 2013c). These studies further revealed the importance of commitment to the use of safe water (Inauen and Mosler, 2013; Inauen et al., 2013c). In summary, in line with previous research on safe water consumption (Huber et al., 2012; Huber and Mosler, 2013; Kraemer and Mosler, 2012; Tamas and Mosler, 2011; Tobias and Berg, 2011) these studies indicate that more committed persons, who perceive safe water collection as more typical, have higher confidence in their abilities to collect safe water, find safe water collection less time consuming and effortful, and who perceive more approval from others to collect arsenic-safe water are more likely to use arsenicsafe water options.

\subsection{Evidence-based promotion of arsenic-safe water consumption}

There are two major implications from this research for enhancing arsenic-safe water consumption: Firstly, it is clear that some technologies are better supported psychologically than others, and are more likely to be easily accepted and used by populations at risk in Bangladesh. Interventions should prioritize these technologies above others, to the extent technically possible. Secondly, interventions should make use of behavior change techniques that can modify psychological predictors of safe water consumption, thereby increasing the number of people using a given water point.

Piped water supply is likely to be accepted and used with minor behavior change efforts, once it is installed. This, however, can be a challenge with regards to financing, because research has shown households' limited willingness to pay (Ahmad et al., 2005). Deep tubewells, in turn, while generally well-accepted, should be accompanied by adequate promotional campaigns to overcome the issues of distance and lack of commitment. Inauen and colleagues employed a systematic approach to develop interventions by targeting the most promising factor of deep tubewell use; commitment strength (Inauen et al., 2013c). To increase commitment, they developed reminders, implementation intentions (simple plans, when, where, and how to perform a behavior, Gollwitzer, 1999) and public commitment (sometimes termed "pledging"), and combined them with risk information. The results of a randomized controlled trial revealed that evidence-based behavior change techniques increased the behavior change effect by $50 \%$ compared to simple information provision (Inauen et al., 2013c). Behavior change techniques can also be combined with technical solutions to facilitate their use. In the case of deep tubewells, for example, a promising suggestion is the installation of two or more suction hand pumps, all drawing water from a single borehole. Thereby, the physical distance for the water collector can be decreased. But also less "spontaneously" accepted and used arsenic-safe water options can be promoted by targeting any of the psychological factors identified above. For wellsharing, for example, the commitment-enhancing behavior change techniques described above increased the number of users by up to 66\% (Inauen and Mosler, 2013).

\section{Technical aspects}

If personal barriers to deep tubewells can be overcome by reducing travel times and through use of behavior change techniques, technical 
reservations still persist on the part of some policy makers. Deep tubewells were not prioritized in the 2004 national policy and implementation plan because of concerns that deep tubewells might not be free of arsenic in some regions, or that abstraction of deep groundwater could induce downward transport of arsenic from contaminated shallow aquifers. However, in the last ten years much has been learned about the geochemical stability of deep groundwater in Bangladesh. Some reports of arsenic in deep tubewells have been shown to be spurious, caused either by inaccurate reports of well depth or by leaks in tubewell joints and piped at shallow depths, which could allow ingress of arsenic-rich shallow groundwater (Ravenscroft et al., 2013). Nonetheless, it is now well-documented that deep groundwater in certain regions (notably parts of Jessore, Satkhira, and the Sylhet basin) can contain arsenic (DPHE/APSU/JICA, 2006), due to specific geological conditions. However, there is no evidence that such contamination is recent or is exacerbated by abstraction. Groundwater flow models predict that deep groundwater could supply domestic drinking water to over $90 \%$ of the arsenic-affected Bengal delta for at least 1000 years before arsenic would reach well screens (Michael and Voss, 2008; Michael and Voss, 2009). The models of Michael and Voss consider unreactive transport, but arsenic migration would be slowed by adsorption onto mineral surfaces. Radloff et al. (2011) have shown that arsenic transport is significantly retarded compared to unreactive solutes. The stability of groundwater quality in deep groundwater is supported by a set of surveys which tested deep tubewells in the coastal belt in 1998, 2006, and 2011. After an average of 19 years of operation, the tubewells showed no change in arsenic, salinity, or other inorganic parameters (Ravenscroft et al., 2013). Thus evidence from modeling, field experiments, and longitudinal surveys suggests that deep aquifers can be expected to provide arsenic-free drinking water for centuries if not millennia (Burgess et al., 2010; Michael and Voss, 2008; Ravenscroft et al., 2013).

Yet, where deep groundwater is free from arsenic, it does not necessarily meet other water quality standards. Salinity in deep tubewells is common in parts of the coastal zone, as well as in the Sylhet basin; and manganese frequently exceeds both the government limit of $0.1 \mathrm{mg} / \mathrm{L}$, and the health-based value of $0.4 \mathrm{mg} / \mathrm{L}$ (WHO, 2011), in central and northern Bangladesh (BBS/UNICEF, 2011). For example, in Sreenagar sub-district, where deep tubewells were installed to avoid arsenic-contaminated shallow groundwater, local drillers normally completed tubewells in brown sands which underlie gray sediments, typically at a depth of 180-220 m. However, Hug et al. surveyed water quality in deep tubewells of the region and found water from this depth to have much higher levels of salinity, manganese, and hardness than shallow groundwater (Hug et al., 2011). People with access to deep tubewells who chose not to use them were shown to be influenced by taste perceptions (Inauen et al., 2013a). Owners also reported damaged pumps that apparently corroded more quickly due to high salinity. A small survey in this area indicated that at intermediate depths of 150$180 \mathrm{~m}$ - where sediments were light-gray rather than brown - arsenic, salinity, manganese and hardness were all within acceptable ranges (Hug et al., 2011). Groundwater from this depth contained moderate levels of iron (2-4 mg/L), but iron in the region is also common in shallow groundwater $(\sim 10 \mathrm{mg} / \mathrm{L})$, and locals are accustomed to the metallic taste. After a series of new tubewells were successfully installed in the $150-180 \mathrm{~m}$ range, local well drillers generally shifted towards this depth to provide water with an acceptable taste, in contrast to the strongly saline taste of deeper groundwater.

The finding of an 'intermediate depth' containing water which is safe not only from arsenic but also from salinity and manganese is echoed by Hossain et al., who found good quality groundwater at $120 \mathrm{~m}$ in Chandpur, one of the most highly arsenic-affected areas in the country (Hossain et al., 2012).

Groundwater quality is spatially highly variable, and safe zones within the deep (or intermediate) aquifer will necessarily be sitespecific. Hug et al. recommend that in areas where deep tubewells are to be installed, safe depth zones should be identified through surveying existing deep tubewells and if possible by installation of a small number of monitoring wells (Hug et al., 2011) which could also serve as drinking water sources. Deep tubewells are relatively inexpensive (Flanagan et al., 2012), so establishment of a network of deep monitoring wells (e.g. at the union level) would not be a great financial burden, and the data generated through such a system could feed into incipient monitoring systems (DPHE/APSU/JICA, 2006), allowing for more rational management of groundwater resources. Maps of existing deep tubewells with depth information and with measured concentrations of arsenic, manganese, salinity and other water parameters over larger areas can be highly useful in delineating regions and depth ranges with a high probability for acceptable water and can help to improve the success rate of newly installed tubewells. This approach was used for the installation of new deep tubewells in the sub-district Monoharganj in Comilla with UNICEF support. Efforts to estimate groundwater salinity with slurry tests directly during the drilling of deep tubewells may also be promising for placing well screens at the optimal depth (Islam, 2012).

\section{Discussion and synthesis}

In three separate but related research efforts, we have found evidence that deep groundwater could be an effective alternative source of safe drinking water over much of the arsenic-affected region. National and local stakeholders involved in arsenic mitigation overwhelmingly considered deep tubewells as the most preferred technical option, because they are perceived as providing high quality drinking water, yet are relatively inexpensive and easy to install with existing human and technical resources. Stakeholders also supported piped water systems, but voiced concerns about the relative lack of experience with these systems, and questions about long-term technical and financial sustainability.

This strong preference for deep tubewells was shared by households in arsenic-affected areas. Deep tubewells are well-supported psychologically, in that action knowledge was high (people know how to use deep tubewells), and descriptive normative factors are positive: people feel that others, including influential people, use these sources. Households also enjoy the cool temperature of deep groundwater (Inauen et al., 2013a).

The studies from the institutional and psychological aspects greatly improved the understanding of the complex issues involving arsenic mitigation activities and the key factors to ensure the success of the measures. The psychological aspect of the analysis found that commitment, self-efficacy and descriptive norms are the most important factors to explain the adoption of arsenic-safe deep tubewells. The institutional stakeholders' opinion analysis suggests that lack of financial means is a constraint and the level of willingness to pay for arsenic-free deep tubewell water is rather low in the affected areas, which seems at first to be contradictory with the findings from the psychological analysis. However, the low willingness to pay makes sense in the local context: most deep tubewells are installed by government programs, and households are asked to make only a nominal contribution to capital costs, but to then fully cover recurring expenses. Willingness to pay on the order of $50 \mathrm{BDT} / \mathrm{month}$ is probably adequate for operation and basic maintenance, and the psychological surveys focused on the acceptance and use of existing safe water options and therefore did not address the challenges of contributing to capital costs of installation.

The psychological surveys identified that potential users of deep tubewells found the long time required to collect water from distant tubewells to be a major disincentive (Inauen et al., 2013a). This is supported by the finding from the stakeholder survey where, the maximum walking distance preferred is within $200 \mathrm{~m}$ from the households (Khan and Yang, 2013). This problem can be tackled in the short term by the use of multiple handpumps tapping a single borehole (Inauen et al., 2013a), and in the long term by increasing deep tubewell density. If the catchment population of a deep tubewell were 65 people (as per 
government guidelines) rather than several hundreds of people (Johnston and Sarker, 2007), travel times would be reduced.

The second limitation to deep tubewells concerns about water quality. Salinity in deep groundwater affects relatively small regions; iron and manganese contamination is more widespread (BBS/UNICEF, 2011). In at least some locations intermediate depth aquifers have been shown to yield water of better quality, without higher arsenic levels.

Regarding the risk of arsenic contamination of pristine deep aquifers, the weight of scientific evidence suggests that the risk is low for most locations, and any contamination would occur over many decades and would never approach the extreme concentrations found in the shallow aquifer. We agree with the position of Ravenscroft et al. that even if tapping deep groundwater to provide arsenic-free drinking water would lead to eventual contamination of the deep aquifer, the public health benefits of substantially reducing arsenic exposure - more quickly than possible by other means - would justify such a strategy (Ravenscroft et al., 2013).

Both the institutional and psychological studies found moderate to strong support for piped water supply systems (Inauen et al., 2013a; Khan et al., Under review; Khan and Yang, 2013). While institutional stakeholders rated piped water as the second most preferred option (after deep groundwater), household survey respondents generally supported piped water more than deep groundwater, in large part because it is perceived to be less time-consuming. However, the experience with such systems in rural Bangladesh is still limited, and limited published information suggests that such systems may not be technically and financially sustainable. One study found that only $57 \%$ of rural piped systems were working at the time of visit (Kabir and Howard, 2007), another found that low levels of Escherichia coli were detected in all systems visited (Gashugi, 2013). Piped water systems in rural Bangladesh are nearly always intermittently operated and without adequate chlorination, raising the real possibility that people might switch from an arsenic-contaminated to a fecally contaminated drinking water source (Lokuge et al., 2004). Improving and extending piped water supplies to cover large areas of rural Bangladesh should be prioritized, but it will take decades before this is fully realized and such systems can deliver safe drinking water to users.

In contrast, deep tubewells can be constructed quickly and relatively cheaply (Flanagan et al., 2012), and could be easily scaled up. If the government would greatly accelerate the construction of deep tubewells; establish monitoring systems to ensure that deep groundwater continues to provide water that is of good chemical quality (considering more than only arsenic); more effectively identify, target, and engage with communities at greater risk for receiving new deep tubewells; and accompany installation programs with evidence-based communication programs, arsenic exposure could be practically eliminated by 2030 (Flanagan et al., 2012).

Finally, well-sharing (i.e. use of a neighbor's arsenic-safe shallow tubewell) is a further arsenic-safe water option that is being promoted with some success in Bangladesh (Ahmed et al., 2006). It is arguably one of the cheapest and simplest arsenic-safe water options. Technically, this option is viable in any location where arsenic contamination is not too dense, so that enough arsenic-safe wells are present. This seems to be the case for a large proportion of the people at risk in Bangladesh (George et al., 2012). No additional infrastructure is required, which is perhaps one reason why this option does not appear in institutional stakeholder preferences (Khan and Yang, 2013), and is only implied, but not explicitly addressed in the National Policy for Arsenic Mitigation (GOB, 2004a). Besides the lack of institutional support, well-sharing is only moderately psychologically accepted (Inauen et al., 2013a), and well-testing services - the prerequisite for identifying arsenic-safe wells - are not readily locally available. Nevertheless, recent research has yielded encouraging results in this regard; people have been shown to pay for arsenic testing when provided with arsenic education (George et al., 2013), and behavior change interventions have been shown to successfully increase people's switching to neighboring safe wells (Inauen and Mosler, 2013). Until private or public safe water supply is extended to the entire population at risk of arsenic consumption, sharing of safe shallow tubewells will remain an important tool in reducing exposure and consequent adverse health impacts.

\section{References}

Ahmad J, Goldar B, Misra S. Value of arsenic-free drinking water to rural households in Bangladesh. J Environ Manage 2005;74:173-85.

Ahmed MF, Ahuja S, Alauddin M, Hug SJ, Lloyd JR, Pfaff A, et al. Ensuring safe drinking water in Bangladesh. Science 2006;314:1687-8.

Bandura A. Self-efficacy: the exercise of control. New York: Freeman; 1997.

BBS/UNICEF. Bangladesh National Drinking Water Quality Survey of 2009. Dhaka: Bangladesh Bureau of Statistics and UNICEF; 2011.

BGS/DPHE. Arsenic contamination of groundwater in Bangladesh. In: Kinniburgh D Smedley P, editors. British Geological Survey and Bangladesh Department of Public Health Engineering, Keyworth, UK, 2001; 2001.

Burgess WG, Hoque MA, Michael HA, Voss CI, Breit GN, Ahmed KM. Vulnerability of deep groundwater in the Bengal Aquifer System to contamination by arsenic. Nat Geosci 2010;3:83-7.

Cialdini RB. Crafting normative messages to protect the environment. Curr Dir Psychol Sci 2003;12:105-9.

DPHE/APSU/JICA. Development of deep aquifer database and preliminary deep aquifer map. Dhaka, Bangladesh: Department of Public Health Engineering, Government of Bangladesh; Arsenic Policy Support Unit; Japan International Cooperation Agency; 2006.

DPHE/JICA. Situation analysis of arsenic mitigation. Dhaka, Bangladesh: Department of Public Health Engineering, Government of Bangladesh, and Japan International Cooperation Agency; 2009

Flanagan SV, Johnston RB, Zheng Y. Arsenic in tube well water in Bangladesh: health and economic impacts and implications for arsenic mitigation. Bull World Health Organ 2012;90:839-46.

Gashugi I. Evaluation of piped water systems performance in arsenic-affected rural areas of Bangladesh. Water quality management. Delft, The Netherlands: MSc, UNESCO-IHE; 2013.

George C, Inauen J, Rahman M, Zheng Y. The effectiveness of educational interventions to enhance the adoption of fee-based arsenic testing in Bangladesh: a cluster randomized controlled trial. Am J Trop Med Hyg 2013;89(1):138-44. http: //dx.doi.org/10.4269/ajtmh.12-0664. Epub 2013 May 28.

George C, van Geen A, Slavkovich V, Singha A, Levy D, Islam T, et al. A cluster-based randomized controlled trial promoting community participation in arsenic mitigation efforts in Singair, Bangladesh. Environ Health 2012;11:41.

GOB. National policy for arsenic mitigation. Government of Bangladesh; 2004a.

GOB. Implementation plan for arsenic mitigation. Government of Bangladesh; 2004b.

Gollwitzer PM. Implementation intentions: strong effects of simple plans. Am Psychol 1999;54:493-503.

Hossain M, Haque A, Alam S, Rahman M, Uddin MR, Sarwar SG, et al. Potentiality of intermediate depth aquifer as a source of arsenic and manganese safe tubewells in Bangladesh. 4th international congress on arsenic in the environment, as 2012, Cairns, Australia; 2012. p. 71-3.

Howard G, Ahmed MF, Shamsuddin AJ, Mahmud SG, Deere D. Risk assessment of arsenic mitigation options in Bangladesh. J Health Popul Nutr 2006;24:346-55.

Huber AC, Bhend S, Mosler H-J. Determinants of exclusive consumption of fluoride-free water: a cross-sectional household study in rural Ethiopia. J Public Health 2012;20: 269-78.

Huber AC, Mosler H-J. Determining behavioral factors for interventions to increase safe water consumption: a cross-sectional field study in rural Ethiopia. Int J Environ Health Res 2013;23:96-107.

Hug SJ, Gaertner D, Roberts L, Schirmer M, Ruettimann T, Rosenberg T, et al Avoiding high concentrations of arsenic, manganese and salinity in deep tubewells in Munshiganj District, Bangladesh. Appl Geochem 2011;26:1077-85.

Inauen J, Hossain MM, Johnston RB, Mosler H-J. Acceptance and use of eight arsenic-safe drinking water options in Bangladesh. PLoS One 2013a;8:e53640.

Inauen J, Mosler H-J. Developing and testing theory-based and evidence-based interventions to promote switching to arsenic-safe wells in Bangladesh. J Health Psychol 2013. http://dx.doi.org/10.1177/1359105313493811.

Inauen J, Tobias R, Mosler H-J. Predicting water-consumption habits for seven arsenic-safe water options in Bangladesh. BMC Public Health 2013b;13:417.

Inauen J, Tobias R, Mosler H-J. The role of commitment strength in enhancing safe water consumption: Mediation analysis of a cluster-randomised trial. British Journal of Health Psychology 2013c. http://dx.doi.org/10.1111/bjhp.12068.

Islam R. Deep aquifer characterisation as an option for safe drinking water supply in Monoharganj Upazila, Comilla. Department of Geology. [M.S. thesis]Dhaka, Bangladesh: University of Dhaka; 2012.

Johnston R, Sarker M. Arsenic mitigation in Bangladesh: national screening data and case studies in three upazilas. J Environ Sci Health A 2007;42:1889-96.

Kabir A, Howard G. Sustainability of arsenic mitigation in Bangladesh: results of a functionality survey. Int J Environ Health Res 2007;17:207-18.

Khan NI, Yang H. Arsenic mitigation in Bangladesh: An analysis of institutional stakeholders' opinions. Sci Total Environ 2013. http://dx.doi.org/10.1016/j.scitotenv.2013.11.007.

Khan NI, Brouwer R, Yang H. Household willingness to pay for arsenic-free drinking water in Bangladesh; 2013w [Under review]. 
Klasen S, Lechtenfeld T, Meier K, Rieckmann J. Benefits trickling away: the health impact of extending access to piped water and sanitation in urban Yemen. J Dev Eff 2012;4: 537-65.

Kraemer SM, Mosler HJ. Effectiveness and effects of promotion strategies for behaviour change: solar water disinfection in Zimbabwe. Appl Psychol Int Rev 2012;61: 392-414.

Lokuge KM, Smith W, Caldwell B, Dear K, Milton AH. The effect of arsenic mitigation interventions on disease burden in Bangladesh. Environ Health Perspect 2004;112:1172-7.

Michael HA, Voss CI. Evaluation of the sustainability of deep groundwater as an arsenic-safe resource in the Bengal Basin. Proc Natl Acad Sci U S A 2008;105:8531-6.

Michael HA, Voss CI. Controls on groundwater flow in the Bengal Basin of India and Bangladesh: regional modeling analysis. Hydrogeol J 2009;17:1561-77.

Mosler $\mathrm{H}-\mathrm{J}$. A systematic approach to behavior change interventions for the water and sanitation sector in developing countries: a conceptual model, a review, and a guideline. Int J Environ Health Res 2012;22:431-49.

Mosler H-J, Blöchliger OR, Inauen J. Personal, social, and situational factors influencing the consumption of drinking water from arsenic-safe deep tubewells in Bangladesh. J Environ Manage 2010;91:1316-23.

National Institute of Population Research and Training (NIPORT). Mitra and associates, ICF International. Bangladesh Demographic and Health Survey 2011. Dhaka, Bangladesh and Calverton, Maryland, USA: NIPORT, Mitra and Associates, and ICF International; 2013

Radloff KA, Zheng Y, Michael HA, Stute M, Bostick BC, Mihajlov I, et al. Arsenic migration to deep groundwater in Bangladesh influenced by adsorption and water demand. Nat Geosci 2011;4:793-8.

Ravenscroft P, McArthur JM, Hoque MA. Stable groundwater quality in deep aquifers of Southern Bangladesh: the case against sustainable abstraction. Sci Total Environ 2013;454-455:627-38.

Schultz PW, Nolan J, Cialdini R, Goldstein N, Griskevicius V. The constructive, destructive, and reconstructive power of social norms. Psychol Sci 2007;18:429-34.

Shafiquzzaman M, Azam MS, Mishima I, Nakajima J. Technical and social evaluation of arsenic mitigation in rural Bangladesh. J Health Popul Nutr 2009;27:674-83.

Tamas A, Mosler H-J. Why do people stop treating contaminated drinking water with solar water disinfection (SODIS)? Health Educ Behav 2011:38:357-66.

Tobias R, Berg M. Sustainable use of arsenic-removing sand filters in Vietnam: psychological and social factors. Environ Sci Technol 2011;45:3260-7.

UNICEF/BBS. Bangladesh National Drinking Water Quality Survey of 2009. Dhaka, Bangladesh: UNICEF/Bangladesh Bureau of Statistics; 2011.

WHO. Guidelines for drinking-water quality. 4th ed. Geneva: World Health Organization; 2011. 